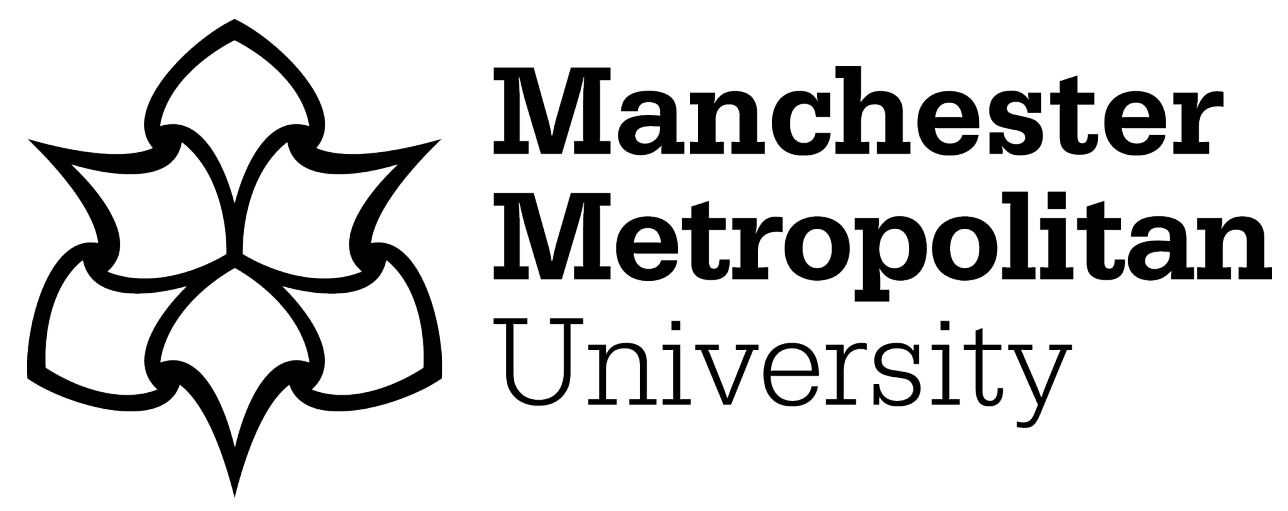

Parnell, D, Stratton, G, Drust, B and Richardson, D (2013) Football in the community schemes: Exploring the effectiveness of an intervention in promoting healthful behaviour change. Soccer and Society, 14 (1). pp. 35-51. ISSN 1466-0970

Downloaded from: https://e-space.mmu.ac.uk/620596/

Publisher: Taylor \& Francis

DOI: https://doi.org/10.1080/14660970.2012.692678

Please cite the published version 


\section{Football in the Community Schemes: exploring the Effectiveness of an Intervention in Promoting Healthful Behaviour Change}

Daniel Parnell, Gareth Stratton, Barry Drust and David Richardson

Research Institute for Sport and Exercise Sciences

Liverpool John Moores University

Liverpool

United Kingdom 


\begin{abstract}
This study aims to examine the effectiveness of a Premier League Football Club's Football in the Community (FitC) schemes intervention in promoting positive healthful behaviour change in children. Specifically, exploring the effectiveness of this intervention from the perspectives of the participants involved (i.e., the researcher, teachers, children and coaches). A range of data collection techniques were utilised to including the principles of ethnography (i.e., immersion, engagement and observations). Alongside conducting focus groups with the children. The results allude to merely 'keeping active children active' via (mostly) fun, football sessions. Results highlight the important contribution the 'coach' plays in the effectiveness of the intervention. Results relating to working practice (i.e., coaching practice and coach recruitment) are discussed and highlighted as areas to be addressed. FitC schemes appear to require a process of positive organisational change to increase their effectiveness in strategically attending to the health agenda.
\end{abstract}

Key words: Premier League, English Football, Football in the Community, Health, Coach. 


\section{Introduction}

Football Clubs, via the development of corporate social responsibility (CSR) strategies and/or Football in the Community (FitC) schemes have a relatively long history of working with the 'community'. [1, 2, 3] The national FitC scheme programme was launched in 1986 , in order to attend to social and sporting changes and building a greater link between clubs and their communities. [4] These FitC schemes had an initial focus on traditional children's coaching schemes to widen access. [5] However, more recently the British Government has identified and championed football as a key vehicle for addressing wider social issues including health, social inclusion, social regeneration and increased participation in (and access to) physical activity. $[6,7,8,5]$

There is a widespread belief that football can be used to promote social inclusion, $[8,9,10,11]$ whilst being championed as a unique vehicle to spread health related messages and subsequently prevent disease and being able to "provide great opportunities to get across key messages about living healthy active lives." [12, 13] Such enthusiasm to financially support football (specifically FitC schemes) as a vehicle for positive change has seen more and more health related projects being funded. [14] Despite the apparent prevalence and subsequent support for such a notion of positive change, there remains little empirical evidence to substantiate football's ability to address such social ills. [15] In this regard, football interventions have tended to lack sufficient guidance (and/or evidence) to explicitly promote positive 
health change. [4] Furthermore, football orientated interventions tend not to utilise coherent research-based procedures that can adequately evidence any 'real' (i.e., observed, articulated, measured and evaluated) effectiveness. Jackson et al., [16, 17] reportedly found no studies to demonstrate the effects of sport based policy interventions on increasing participation and/or promoting healthy behaviour. Similarly, Tacon [18] reinforced such frustrations by calling for a need for more rigorous evaluation of FitC schemes. Such calls for more supporting evidence to substantiate the use of football as a vehicle for social change highlights the fact that current monitoring and evaluation processes do not fairly reflect the true nature, complexity and subsequent outcomes of the (apparently) numerous interventions. [19, 4, 18]

The purpose of this study is to examine the effectiveness of a Premier League Football Club's FitC intervention in promoting positive healthful (i.e., physical activity, positive lifestyle) behaviour change. This study will aim to identify and explore the day-to-day working practices of those involved within FitC and the subsequent the effectiveness of this initiative from the perspectives of the participants involved (i.e., the researcher, teachers, children and coaches). The results from the study will provide key insights into the factors that influence the effectiveness of FitC delivered interventions, thereby providing guidance to help inform managers and coaches within the broader football and health environment, to create more effective interventions and coaches. 


\section{Method}

\section{Study Design and Description of the Intervention}

This study formed part of an extensive reconnaissance phase within a longitudinal collaborative action research project with the community arm of a Premier League football club. This extensive reconnaissance phase spanned a 10-month period (August 2006-June 2007). The reconnaissance phase was utilised in order to better understand the nature of existence within the workplace (i.e., the FitC scheme). [20] The reconnaissance phase included a multi-method evaluation of a 16-week long FitC coaching intervention (i.e., targeting primary school children). [19, 18] This evaluation was underpinned by the principles of ethnography and observational research by the first author in order to 'get close' to those involved (i.e., FitC staff/coaches, schools, teachers and children). [21, 22] The research also utilised focus groups with the children involved in the intervention. [23]

\section{Participants and setting}

The 16 week long community coaching intervention involved six FitC community coaches and their senior management $(n=2)$. The intervention was delivered within the school setting either indoor (typically in the school hall or gymnasia) or outside (typically on the school field or playground). Each school $(n=4)$ received 16 coaching sessions, each lasting approximately 1 hour. The FitC community coaching intervention was delivered during the academic year and took place straight after school. All schools were situated in a deprived 
area of the City of Liverpool, in the North West region of England, as indicated by the Indices of Multiple Deprivation. [24] Each of the four participating schools was selected independently of the first author by the FitC coaches. Each school initially selected 16 children to engage within their particular intervention (as this coincided with coach to child ratio best practice guidelines). The link or head teacher within each school pre-selected the children for each coaching session. Fifty-seven children (males $n=40$, females $\mathrm{n}=17$ ) were recruited in total. All children were aged 8-11 years of age. Signed informed parental consent was obtained from all parent/guardians of the 57 children and from the Head teacher of the schools. Ethical approval was obtained from Liverpool John Moores University Ethics Committee.

\section{Measures and Assessment Procedures}

\section{Immersion and Observation}

During the reconnaissance period the first author utilised principles of ethnography and observational research in order to become immersed in the working environment of the FitC scheme. [21, 22] The first author (typically) spent 2 days per week within the FitC scheme. These two days included attendance at each coaching session of the 16-week long intervention (i.e., at each of the 4 schools). During this period, the first author adopted a range of informal and open approaches to data collection (e.g., informal conversations). Such an approach enabled the first author to explore issues as they evolved both 'on the ground' (i.e., with coaches, children, teachers, parents) and with senior management. In this sense, the first author 
recognised the importance of not being perceived to be chasing data and that ultimately exchanges should be as 'typical' and/or as 'natural' as possible in order to achieve acceptance within the environment of the FitC. Additionally, the first author recorded personal reflections and observations through informal field notes and a reflective diary. [21, 22, 25] The reflective diary and the informal field notes were continually developed in an attempt to capture the context, culture and practice of the FitC schemes and subsequent opinions and perceptions of all involved. [26, 27]

Physical Activity Child centred research techniques were adopted in order to construct a comprehensive understanding of the physical activity behaviour and lifestyle changes for each child participant across the intervention. The child centred approach ensured that the children were viewed as competent social actors as opposed to being consumed within the family unit. [28]

Focus Groups: Focus groups were conducted at week $8(n=10)$ (see table 1) and week $16(n=10)$ (see table 2) of the intervention. The focus groups provided the researcher with an opportunity to talk and engage directly with the child participants in order to better understand, elaborate and clarify ideas and (any) issues (i.e., barriers, perceptions to physical activity); making sense of their life, as they live it. [29, 30, 31] The content and focus for discussion within each part of the focus group was primarily deductively driven by previous literature relating to the aim(s) of each focus group. The focus group at week 8, explored the children's understanding, perceptions, barriers, and habits toward physical activity (see table 1). 
Table 1: The focus group delivered at week 8 (physical activity)

\section{Phase 1}

'Introduction \& Familiarisation': Aimed to enable the first author to relax the children and encourage openness. Whilst reiterating the confidentiality of the conversations within the focus group the author demonstrated the need for clarity in speech, patience to express opinions, duration and purpose of the group discussion. [32]

\section{Phase 2}

Aim: To develop an understanding of what and how the children's perceived understanding of physical activity, inactivity, healthy and unhealthy behaviours. The children engaged in a task where they work together to identify whether a range of typical/normal activities and/or foods were aligned with active, inactive, healthy or unhealthy lifestyles or behaviours. This group work allowed the children to begin expressing their opinions within their discussion. [33]

\section{Phase 3}

Aim: To specifically build an understanding of what the children's perceptions of, and habits towards their most enjoyable physical activity were. The first author then prompted discussion on and around the children's perceptions of the barriers toward physical activity. This information enabled a clearer picture of the children's behaviour and lifestyles to emerge. [34]

\section{Phase 4}

Aim: To develop an understanding of the barriers to physical activity (similar to above), however with an emphasis on why 'others' do not take part. Here the first author encouraged the children to express their perceptions of why 'other' children were inactive and what could be done to help these children become more active. $[35,36]$

\section{Phase 5}

Aim: To bring the focus group to a close by giving the children an opportunity to reflect on the previous discussions.

The focus group at week 16, explored the children's perceptions of the FitC coaching post-intervention (see table 2). Both tables 1 and 2 outline the structure of the focus groups at weeks 8 and 16, respectively.

Table 2: The focus group delivered at week 16 (perceptions of the intervention)

\section{Phase 1}

Aim: To introduce and clarify the purpose and duration of the focus group. Here the author emphasised the importance of the children's views and opinions concerning the coaching intervention and how there were now actively engaged in developing the intervention to ensure future sessions included the most enjoyable and fun elements. [37, 38, 39] 
Aim: To utilise the first author's attendance at the session within the intervention. Here the author and children reminisce on the activities and content delivered within the intervention. With each activity the author prompted responses and discussion regarding the children's perception of a specific activity. Phase 2 also encouraged children to support their opinions and reflections with examples and feelings. $[40,41,37,39]$

Phase 3

Aim: To explore the positive and negative aspects of the intervention. As in phase 2 the author probes deeper into opinions and expressions seeking examples, feelings and, where relevant, potential ways to promote or prevent similar experiences in the future. [36, 38]

\section{Phase 4}

Aim: To draw a close to the focus group the first author utilised the 'Aladdin's Lamp' activity. Specifically, the children were asked to recall their most memorable activity/element, and make their 'wish' for the future concerning the coaching intervention. $[42,43]$

In order to encourage the children to speak openly and freely, each focus group was facilitated by the researcher in the absence of potentially dominant figures such as teachers. [23] In addition, the researcher was sure to highlight the notions of 'trust' and confidentiality with the children within the introduction to the focus group. Moreover, it has been highlighted that building a rapport and/or trust with children (usually) involves spending time (e.g., extensive ethnographic observations, informal interactions and conversations) with the children prior to engaging in any formal research task. [44, 45] In this regard the researcher, prior to the initial focus group (i.e., the focus group at week 8), spent many hours (typically through 2 or 3 visits per week) with the children. The researcher was also cognisant of adopting a voice and mode of communication that recognised the children's level of cognitive and linguistic development. Such recognition of the children's contextual voice and subsequent mutual understanding of each other (i.e., the first author and the children) can only be gained through long term engagement. Furthermore, the utilisation of pictures, material and aids (e.g., utilising scenarios such as the healthy and unhealthy twin sisters to stimulate discussion about healthful behaviours, physical activity and lifestyles) within the familiar setting of the school enabled the researcher to communicate in a way that children would 
more readily understand. [46, 47,38$]$ The adoption of a variety of methods and tools within the focus group ensured that the focus group activity was fun and engaging and, critically, kept the attention of the children. [48] The researcher adopted recommendations that the optimum size of group should be (around) 5 children and that the range of ages between the children should be kept to a minimum. $[49,50,51,48]$ In this regard, the first author interpreted this guideline as no more than a 1-2 years age difference between the children. Whilst Greenbaum [49] and Hill, Laybourn and Borland [51] advocate single sex focus groups the researcher felt that, given the extensive reconnaissance and subsequent knowledge accumulation and understanding of the characters and personalities within the groups of children that, in this instance a mixed sex group would offer positive interactions and would not negatively affect the overall aims of the focus groups. The researcher's extensive engagement allowed for informed selection of the children's groupings, which enabled them to have an optimum experience together within the focus group.

\section{Data Analysis}

The key issues that emerged from the reconnaissance phase are highlighted throughout the results and discussion section. Verbatim citations are utilised to illustrate the contextual features of the participants that serve to illuminate the rich detail of the collected data and is identified in italics. The first author's field note extracts and personal reflections are evidenced as indentations, single spaces lines and a smaller (font 10) within the text. 
The focus group data were transcribed verbatim and analysed using the principles of content analysis. $[52,53,54]$ The basic tenets of content analysis allowed for groups and/or clusters of similar sentiment emerge. Further clustering of this data enabled the emergence of key issues and/or themes from within the focus group data. Focus group data represents significant moments and dialogue and is presented in the results and discussion section as indented sections of text with single space lines and a smaller (font 10) within the text. [55] Staying close to the data is the most powerful means of telling the story, whilst also ensuring that data interpretation, where possible, is undertaken using the participant's (i.e., children's) language, rather than that of the researcher. $[56,57]$

A first person writing style was adopted in elements of the results and discussion in order to help contextualise the data and move the story on for the reader. $[58,59]$ Again, the themes discussed are those that have emerged from the cursory content analysis undertaken throughout the research. Pseudonyms are used for children, teachers, schools, FitC staff, community coaches and senior management throughout.

\section{Results/Discussion}

The following results and discussion section offers, what the authors perceive to be, the relevant (but not exhaustive) issues emerging from the expansive 
data collected. The data suggests that the intervention was unable to influence positive healthful behaviour changes in the children involved, but was able to maintain activity in already active participants. For example the child participants stated: "I play with my brother", "I play out with my family", and "I like to play football with my mate Aaron". The fun and enjoyable nature of the intervention and the hype and excitement within the children, teachers and schools involved in the programme seemed to be an important aspect of keeping the children engaged/participating in activity. For example: "I look forward to the sessions all weekend and all day. Paul (the coach) teaches us lots of skills and we play big matches" (Jonas aged 10 years), "Right! Come on children, the wonderful coaches are here!" (Mary: a Primary School Teacher). Despite the overwhelming approval of the majority of children there were some negative comments focused on the coach within the focus groups:

Charlie (aged 9): $\quad$ If he (the coach) turned up on time we could get started straight away Titus (aged 10): $\quad$ The coach told me to shut up.

Whilst such comments are not a wholesale representation from all of the children, they do allude to possible negative memories of the intervention and specifically the coach. The below focus group extract details the children's comments highlighting dissatisfaction and negative memories pertaining to the intervention:

Alan (aged 11): ...she just used to shout and used to send you out for... Jen (aged 10): For nothing. 


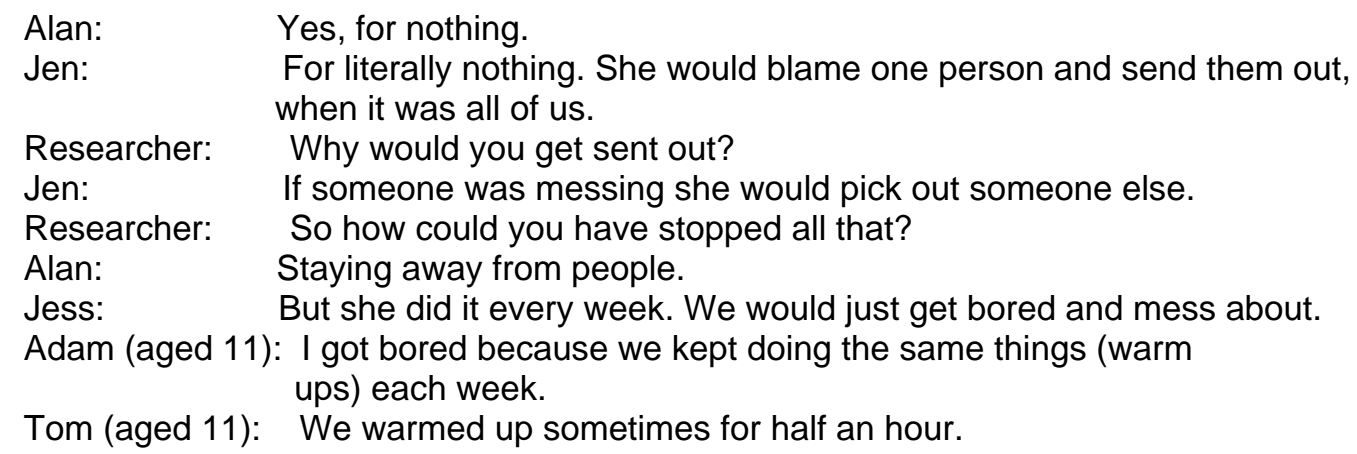

The above focus groups data together with the comments from the children and further contextual information from the researcher, children and teachers, suggests that this coaching intervention provided excitement, enjoyment and fun for (the majority of) those involved. $[41,60]$ However, due to the apparent ineffective working practices of some coaches throughout the intervention (and on specific occasions) the potential effectiveness of this intervention has been limited

These ineffective working practices appeared within the delivery of the intervention surrounding the role of 'the coach' and their respective coaching practice. The following discussion explores the role of the coach, alluding to coaching practice, coach recruitment, aspirations and skill base. In order to maximise the potential impact or effectiveness of healthful behaviour promotion work within a FitC schemes it appears that a number of working practices must be addressed to tackle some of the observed issues present within the intervention. 
Attrition rate: One of the first issues to surface within the intervention was the declining participation figures in the data. Of the original 57 children that were involved prior to the intervention, 14 children dropped out before the first session had even taken place. The total dropout rate for the entire intervention was $54 \%(n=31)$. I discussed this with one of the teachers:

"Ok Sandra (Primary School Teacher), we have experienced quite a bit of drop out with the children on the programme. Do you have any idea why this is and how we could possibly get them back in?". "Really? I didn't know. Nothing has been said to me?"

I thought, how can she be surprised? Does she not know what's going on? I asked Sandra why she thought the children had left the programme and she didn't really have any ideas. She said "all the children love football and most play in the school team". What!? Great they love football; they play in the school football team...so why were they dropping out? This is free football from a Premier League Club!

This relatively high attrition rate appeared to go unnoticed, unrecognised or even investigated by the coaches or the teachers. Although poor adherence isn't uncommon within interventions its presence is cause for concern especially given that the children were apparently already 'active' in their school football team. [61]

I managed to ask some children why they dropped out of the programme, Claire (10 year old girl) "I don't know I don't really like football". Ibrahim (9 year old boy) "the sessions aren't challenging enough". I explored this comment further with Ibrahim, specifically seeking his expectations and his perceptions before speaking with other children. It appeared that the sessions were in some cases 'too challenging' and 'too structured', which frustrated the children, specifically Ibrahim who didn't want to admit this given his normally confident and outgoing character. In essence, I knew that all that these kids wanted was to 'just play football and have fun'.

Maintaining adherence and participation should be the cornerstone of interventions seeking to promote positive health change. It was apparent that I 
must explore this further within the coaching sessions, in a bid to fully understand coaching practice, delivery and the subsequent impact on the children's experience.

The Coach and Coaching Practice: It was evident that (generally) the children did not want to engage in long sessions that were focused on improving technical skills or tactical play. Overly prescriptive approaches to coaching have been reported as a factor in reducing participation. [62] In this regard, I was able to empathise with the children's frustrations as throughout the intervention I witnessed a number of situations where the coaches attempted to deliver routine or traditional (performance oriented) football drills. In one particular instance within a session at Kingsway Primary School frustrations (between the coach/practitioners) became evident:

Today Alan (the coach) arrived 5 minutes before the session was due to start. I had arrived early today as usual.

I stood to the side of the session - casually leaning against a metal railing, watching the scene unfold. Alan started, as he usually does with warm up drills and dynamic stretches. I can't help, but remember my days coaching...it all looks very professional. Too professional perhaps. Professional, but not in a 'fun' way. As I watched the children within the coned area, there were a few laughs and bits of banter "Aaron you run like a giraffe!" gets some giggles, but some of them look abit tired - not the physical 'puffed out' tried, but bored. Some are walking around, strolling almost, shoulders down, a bit lack-lustre. After a slow start and 10 minutes into the warm up, my concerns were confirmed as murmurings of "I'm tired" and "Can we play yet?" littered the air. To be fair to the kids, I was pretty bored myself. We were 5 weeks in to the scheme and this warm up was virtually the same as every other one that either Alan or Jack (another community coach) who shared the session with Alan throughout the intervention, had delivered. Following the warm up, the session flowed into some basic passing moves between the children. This moved into a complex passing drill involving the whole group of children working together. We've moved from boring to complex in one fell swoop! This was an intricate drill, one that some similar aged academy players would struggle with, never mind the group we have here. The children really struggled and became frustrated and impatient. Mistake after mistake, missed pass after missed pass. Stop, start, stop start...

I couldn't help wonder why Alan persisted. I kept thinking, but I was powerless. I can feel my head, screaming 'change the drill!! Why don't you just change the drill? I'm 
shouting'. He can't hear. It's not my job to intervene. Can't you see the children are frustrated? Just change the drill!

Alan (and other coaches involved in the intervention) did not appear to (formally or officially) plan any sessions. My understanding was that Alan plans all his sessions 'in his head'...or at least I hoped. Given the difficulty that the children were having with the task it would appear sensible/appropriate (to any informed coach) to adapt or change the session to a more suitable practice or game equivalent and relevant to the ability of the group. [63] What followed developed into something nothing short of a spectacle:

Undeterred, Alan continued to persevere with the drill, "Come on, surely you can do this?" The children were becoming clearly frustrated (with some looking to me with desperate expressions). Alan then turned to me. With subtle manoeuvring I retreated back to my 'leaning' role, busying myself away from the session. "If they can't do this simple task they will never make it (as a professional)". With a slight wince, I tried to hide my disbelief at Alan's comment. Not only could the children hear the comment, but it also confirmed that Alan was approaching the sessions with a performance oriented lens. Alan, having received a neutral dismissal of his remark from me turned to the children, "We're not stopping this (drill) until you do it!" The children themselves, who already appeared de-motivated and frustrated, responded in unison, "We just want to play!" Further calls for a match or game continued. The session finally came to a painful end, with Alan spluttering to me "I have washed my hands with them (the children). I've had enough". With that he collected the balls in and busied himself packing the balls away. What's happening I thought? "Are they having a match?" I asked, which was met with a curt reply "No". Alan was actually ending the session, no de-brief, no feedback, not even a goodbye! These kids didn't deserve this. I spoke to them and said we, (yes the preverbal we) would see them next week. The kids weren't impressed! As Alan sloped off towards the car, I felt a huge sense of disappointed. Disappointment shared with the kids.

Alan is a community coach with a number of years of experience working with young people in a range of roles. Alan has accrued his 'badges' (required by the English Football Association and Football in general to coach children) through his role within the FitC scheme. There are concerns here that although Alan has appropriate accreditation, it would appear that he is less 
able to translate his skill set to fulfil and meet the needs and requirements of a community oriented (i.e., predominantly recreational) session. In effect, the FA's accreditation programme does not equip the 'community coach' with a full skill set to work across such complex situations such as this. [64] In this sense, whilst Alan was able to demonstrate high level technical instruction, he failed to give feedback (positive), reinforcement and supportive behaviour, which has been associated with higher player perceptions of competence, enjoyment, self-esteem and self confidence. [65, 66] Such inadequacies suggest that Alan is failing in his attempt to encourage participation and/or the promotion of physical activity (i.e., whether these children are future performers or not). His coaching practice fails to embrace a physical activity remit and appears detrimental to the self-worth that these kids may have had. Despite this, when Alan was asked informally, about what he thought the sessions were all about, he replied:

Enjoyment, it's the taking part that we (the FitC scheme) try to look at; we don't want to go into the schools and spot the next Stephen Gerard or Tim Cahill. We want to look to get everybody involved, so the enjoyment is the main part. If they are enjoying it you've obviously achieved what you have gone in there to do.

Whilst Alan obviously, understands the need to make sessions fun, it appears that he cannot actually deliver to this agenda if the children he is coaching are not skilled. Somewhere between Alan becoming a regular 'community coach', completing his coaching qualifications and joining the FitC scheme, he has developed some negative working practices. In this sense, his interpretation of a 'fun and enjoyable' focused session would typically involve a pass and 
move drill. Importantly, it has been highlighted that situational factors such as national (the Football Association) and organisational culture (of the FitC scheme) may have played an influence on the behaviour of the coach. [67]

\section{Recruiting the right person for the job:}

To become employed as a coach within the FitC scheme you must possess a UEFA B, or at least a Football Association Level 2, coaching qualification. On appointment, newly recruited staff undertake an informal induction within the FitC scheme. Such an induction includes spending time observing an established coach. Whilst such an approach can be viewed as good practice it can also expose new recruits to poor practice. In this regard, if new recruits shadow a coach that is not 'on message' or not delivering to a high quality then these new coaches can be organisationally socialised in to poor practice. [68] It appeared that new coaches delivered what they had observed and learnt from more experienced coaches, "You watch and speak to other coaches for a while, but then you just deliver the sessions. It's not hard, just basic football sessions" (Alan). Educational literature relating to newly recruited teachers, like coaches suggest that new employees endeavour to 'fit in' to an organisation, as much as learn to 'coach'. [69] For example: Alan had been through this process and may have inherited elements of poor practice from existing (more experienced) coaching staff. Similarly, early career coaches (similar to teachers) may be ill-equipped to deal with the problems and difficulties (i.e., organisational, cultural, practice) that they face, as they encounter the pressures to conform. [70] Therefore, new coaches are likely to 
inherit the (in some cases entrenched) practices of the existing coaching staff. This negative socialisation appears evident in Alan's case and the following extract outlines the discrete introductory experiences of two other community coaches:

Josh: when you join you shadow a more senior coach and so for the first maybe three or four weeks you won't actually have to take a session but just watch and pick up ideas on and get a feel for how the sessions run and what type of children you are mainly dealing with.

Pete: I didn't have any experience of working in schools when I started. During my enrolment I would have liked to have had some time to shadow a coach but because when I joined there weren't many coaches they didn't really have the resources for me to be shadowing another coach. I went straight into it.

If an organisation aspires to effective and efficient working practices then the initial attempt at providing a mentor (to shadow/support) newly appointed coaches is laudable. However, given that there were concerns expressed over the existing practices of (some) of the coaches, it is likely that elements of this poor practice will permeate newly appointed staff. In this sense, new recruits are highly likely to become organisationally socialised through aspects of poor practice. This situation is further compounded by the fact that the enrolment process does not appear to encourage or promote change or creativity in practice. Knowles et al. [71] state the importance of reflective practice on coach development and progressive positive change. It would appear that (some) of the practices adopted here are more likely to encourage conformity and social alignment with workplace norms. Moreover, it appeared that the aspirations of the coach in relation to coaching orientation (i.e., participation or performance) appeared to impact the fluency of coaching practice and may be a direct product of a the requirement to hold an Football 
Association Level 2 or UEFA B qualification. Such qualifications tend to be more aligned with academy (performance) rather than community (participation) coaching practice.

\section{Community or Academy: where do you want to be?}

When exploring the data collected from the coaches $(n=6)$, it appeared that the three coaches that aspired to stay working within the FitC scheme, from my personal observations and comments from the children, delivered the most fluent sessions, compared to those that aspired to work in professional football academies or centres of excellences. It was no surprise when it emerged that Alan's aspirations lay beyond the community coaching environment and the FitC scheme, "I will probably move on from the community, and move to something of a higher level of coaching." All 6 coaches aspired to 'up-skill' their coaching qualifications, despite stating that they felt that their core work did not need this additional training. It appeared that coaches that were typically used to coaching competent (i.e., football competent) children, were now faced with children whom were neither particularly skilful nor competent. Subsequently, the coaches experienced some behavioural problems with the children within the intervention. During these challenging situations some coaches were ill-equipped to neither deal with nor attribute a specific cause to the behaviour. Jason was a young coach who worked on both an elite adult level and within the community interventions. However, before joining the FitC scheme he had no prior experience of school-based coaching. Jason was subsequently asked (within 
an informal interview) whether he found any problems with the sessions/programme, to which he responded:

I don't think there have been any sort of massive problems that stick out, but then that really depends on what your definition of a problem is. We have had some sessions that have broken down because of the kids behaviour, but that happens to an extent in almost any and every session, but in terms of the structure and delivery of the programme - no I wouldn't say there have been any major problems.

The results appear to show that the coach and their respective skills and ability have an influence on the fluency of their session and the rapport that they are able to develop with the children. These findings are similar to those that suggest that expert coaches are better able to make more effective decisions regarding appropriate behaviour and subsequent actions in any given situation. [72]

\section{Conclusion}

The purpose of this study was to examine the effectiveness of a Premier League Football Club's FitC intervention in promoting healthful behaviour change. It appears that, from the collective focus group data, comments from the children and further contextual information from the researcher, for the children and teachers this coaching intervention provided excitement, enjoyment and fun for (the majority of) those involved. [41, 60] In particular, the intervention has provided an opportunity for the majority of already active children to engage in further physical activity opportunities. Whilst this positive experience is highly laudable, it appears that due to the deficiencies (or gaps) 
in the coaches' skill base, and subsequent inappropriate working practices, the potential effectiveness of this intervention has been limited to 'keeping active children active, through fun and enjoyable sessions. In order to maximise the potential impact or effectiveness of healthful behaviour promotion work within a FitC schemes it appears a number of working practices must be addressed.

In order to effectively address and target healthful behaviour the focus of such interventions (i.e., to promote positive healthful behaviour change) needs to embrace and include more 'at risk' or perhaps 'in need' populations (i.e., those not engaged in physical activity and/or are overweight or obese). Further to this, concerns over poor coaching practice (although isolated and coach dependent) must be challenged and tackled. The recruitment process appears to be contributing factor to this issue. Therefore FitC schemes must make sure the right people with the right skills are employed (i.e., including the coaches' skill base, qualifications and experience across populations) in order to ensure that FitC schemes can attend to the increasingly complex social and health agendas that they are being asked to tackle. Moreover, FitC schemes must provide newly recruited (and existing) coaches with relevant and specialised training opportunities to 'skill up', as part of a commitment to relevant continued professional development (CPD). Such an up-skilling process through (say) co-ordinated CPD opportunities will enable effective delivery across projects and agendas and not necessarily be reliant on the Football Association's incremental levels of (performance based) coaching qualifications and/or coaching licenses 
In light of these findings FitC schemes appear to possess a number of potentially positive factors that may provide a background for such interventions to deliver positive results in community based football projects. However, it is apparent that schemes operated by FitC may require a number of positive organisational changes. To maximise the potential they have, to develop and utilise effective working practices that specifically relate to the individuals who are involved in the direct delivery of the programmes.

\section{References}

1 Breitbath, T. and P. Harris. 'The Role of Corporate Social Responsibility in the Football Business: Towards the Development of a Conceptual Model'. European Sports Management Quarterly 8, no 2 (2008): 179-206.

2 Russell, D. 'Football and the English: A Social History of Association Football in England, 1863-1995'. Preston: Carnegie, 1997.

3 Walters, G. and S. Chadwick. 'Corporate citizenship in football: delivering strategic benefits through stakeholder engagement'. Management Decision 47, no 1 (2009): 51-66.

4 Brown, A., T. Crabbe and G. Mellor. 'Football and its Communities: Final Report'. London and Manchester: Football Foundation and Manchester Metropolitan University (2006).

5 Mellor, G. 'POLITICS, THEORY AND PRACTICE: 'The Janus-faced sport': English football, community and the legacy of the 'third way'. Soccer and Society 9, no 3 (2008): 313-324.

6 Department for Culture, Media and Sport. 'Report to the Social Exclusion Unit - Arts and Sports'. London: HMSO (1999). 
7 Football Association. The Football Development Strategy 2001-2006. London: The Football Association (2001).

8 Department of Health. 'Football and Health'. 23 May 2005, accessed March 72011 ,

<http://www.dh.gov.uk/en/Publicationsandstatistics/Publications/PublicationsP olicyAndGuidance/DH 4111800>

9 Collin, M., I. Henry., B. Houlihan and J. Buller. 'Sport and Social Inclusion: A Report to the Department for Culture, Media and Sport', Loughborough University: Institute of Sport and Leisure Policy (1999).

10 Football Task Force. 'Investing in the Community, as submission by the Football Task Force to the Minister for Sport'. 11January 1999, accessed January 10 2011, <http://www.sportdevelopment.org.uk/ftfcommunity.pdf>

11 Department of Culture, Media and Sport. 'Building on PAT 10: Progress Report on Social Inclusion'. London: DCMS (2001), accessed January 10 2011, < http://www.sportdevelopment.org.uk/reportonpat10.pdf>

12 FIFA. 'A Medical Initiative'. Accessed March 8 2011,

<http://www.fifa.com/aboutfifa/worldwideprograms/wininafrica/medicalinitiative $\underline{. \mathrm{html}>}$

13 Department of Health. 'Kick Start to Health'. May 2005, accessed March 8 2011, <http://gov-news.org/gov/uk/news/kick start to health/17770.html>

14 The Premier League. 'Creating Chances 2008/09 Report'. 2009, accessed March 2011, <http://www.premierleague.com/page/CommunityPL/0, 12306,00.html>

15 Long, J. and I. Sanderson. 'The Social Benefit of Sport: Where's the proof?' In Sport in the City, ed. C. Gratton. and I. Henry. London: Routledge. 2001

16 Jackson, N., F. Howes., S. Gupta., J. Doyle and E. Waters. 'Policy Interventions Implemented Through Sporting Organisations for Promoting 
Healthy Behaviour Change (Review)', The Cochrane Collaboration, Wiley (2005a).

17 Jackson, N., F. Howes., S. Gupta., J. Doyle and E. Waters. 'Interventions Implemented Through Sporting Organisations for Increasing Participation in Sport (Review)', The Cochrane Collaboration, Wiley (2005b).

18 Tacon, R. 'Football and social inclusion: Evaluating social policy', Managing Leisure 12, no 1 (2007) 1-23.

19 Schoor, L. Common Purpose: Strengthening Families and Neighbourhoods to Rebuild America. New York: Anchor Books, 1997.

20 Carr, W. and S. Kemmis. Becoming Critical: Knowing Through Action Research. Lewes: Falmer Press, 1986.

21 Hammersley, M. and P. Atkinson. Ethnography: Principles in Practice. London: Routledge, 1995.

22 Hammersley, M. Whats Wrong with Ethnography? Methodological Explorations. London: Routledge, 1992.

23 Biddle, S., K.R. Fox and S.H. Boutcher. Physical Activity and Psychological Well-Being. New York: Routledge, 2000.

24 Liverpool City Council. 'The Indices of Multiple Deprivation 2007'. 2007, accessed March 8 2011,

<http://liverpool.gov.uk/Images/IndicesDeprivation07.pdf>

25 Richardson, D., D. Gilbourne and M. Littlewood. 'Developing Support Mechanisms for Elite Young Players in a Professional Soccer Academy'. European Sport Management Quarterly 4, no. 4 (2004): 195-214.

26 McFee, G. 'Triangulation in research: Two confusions'. Educational Research 34, no 3 (1992): 173-183.

27 Krane, V. and S.M. Baird. 'Using ethnography in applied sport psychology'. Journal of Applied Sports Psychology 17 (2005): 87-107. 
28 Qvortup, J. 'A voice for children in statistical and social accounting. A plea for children's rights to be heard'. In Considering and Reconstructing Childhood: Contemporary Issues in the Sociological Study of Childhood, ed. A. James and A. Prout. London: Falmer Press. 1990

29 Woodhouse, M., P. Light and R. Carr. Child Development in Social Context 3: Growing up in a changing society. London: Routledge, 1991.

30 Baker, T.L. Doing Social Research 2. New York: McGraw-Hill Inc, 1994.

31 Hill, M., A. Laybourn and M. Carr. 'Engaging with primary-aged children about their emotions and well-being: methodological considerations'. Children and Society 10 (1996): 129-44.

32 Morgan, M., S. Gibbs. K. Maxwell and N.Britten. 'Hearing children's voices: Methodological issues in conducting focus groups with children aged 7-11 years'. Qualitative Research 2, no 1 (2002): 5-20.

33 Williams, T., N. Wetton and A. Moon. A Picture Of Health: What Do You Do That Makes You Healthy and Keeps You Healthy? London: Health Education Authority, 1989.

34 Baranowski, T., C.L. Perry and G.S. Parcel. 'How Individuals, Environments, and Health Behavior Interact'. In Health Behavior and Health Education: Theory, Research and Practice 3, ed. K. Glanz, B.K. Rimer, and F.M. Lewis. San Francisco, CA: Jossey-Bass. 2002

35 Backett, K.C. and H. Alexander. 'Talking to young children about health: methods and findings'. Health Education Journal 50 (1991): 34-37.

36 Kaladjian, L. 'Children qualitative research past and present'. Article Archives 1996, accessed March $10 \quad$ 2011, <http://www.quirks.com/articles/a1996/19961202.aspx?searchID=155295825 $>$

37 Telama, R., X. Yang, L. Laasko and J. Viikari. 'Physical activity in childhood and adolescence as predictor of physical activity in young adulthood'. American Journal of Preventative Medicine 32 (1997): 1617-1622. 
38 Porcellato, L., L. Dugdill and J. Springett. 'Using focus groups to explore children's perceptions of smoking: reflections on practice'. Health Education 101, no 6 (2002): 310-320.

39 Westerstahl, M., M. Barenkow-Bergkvist and E. Jansson. 'Low Physical Activity among Adolescents in Practical Education'. Scandinavian Journal of Medicine and Science in Sports 15 (2005): 287-297.

40 Raitakari, O.T., K.V.K. Porkka, S. Taimela, S. Telama, L. Rasanen and J.S.A. Viikari. 'Effects of Persistent Physical Activity and Inactivity on Coronary Risk Factors in Children and Young Adults'. Journal of the American Dietetic Association 95 (1995): 248-256.

41 Craig, S., J. Goldberg and W.H. Diet. 'Correlates of Physical Activity among Fifth and Eighth Graders'. Preventative Medicine 25 (1996): 506-513.

42 Jewett, D. Helping Children Cope with Separation and Loss. Batsford, 1984.

43 Hill, M. and J. Triseliotis. 'Who do you think you are? Towards understanding adopted children's sense of identity'. In Through the Lookingglass: Children and Health Promotion, ed. J. Ross, and V. Bergum. Ottawa: Canadian Public Health Association, 1990

44 James, A. Childhood Identities. Edinburgh University Press, 1993.

45 Opie, I. The People in the Playground. Oxford University Press, 1994.

46 Spencer, J.R. and R. Flin. The Evidence of Children. Blackstone Press, 1991.

47 Garbarino, J., F.M. Stott and Erikson Institute. What Children Can Tell Us. San Francisco: Jossey-Bass, 1992.

48 Hill, M., A. Laybourn and M. Borland. 'Engaging with Primary-aged Children about their Emotions and Well-being: Methodological Considerations'. Children and Society 10 (1996): 129-144. 
49 Greenbaum, T.L. The Practical Handbook and Guide to Focus Group Research. Lexington: Lexington Books, 1987.

50 Hill, M. 'Children's role in domestic economy'. Journal of Consumer Studies and Home Economics 16 (1992): 33-50.

51 Hill, M., A. Laybourn and M. Borland. Children's Well-being. Edinburgh: Report to the Health Education Board for Scotland, 1995.

52 Scanlan, T.K., K. Ravizza and G.L. Stein. 'An in-depth study of former elite skaters: I. Introduction to the project'. Journal of Sport and Exercise Psychology 11 (1989a): 54-64.

53 Côté, J., J.H. Salmela, A. Baria and S. Russell. 'Organising and interpreting unstructured qualitative data'. The Sport Psychologist 7 (1993): 127-137.

54 Biddle, S.J.H., D. Markland, D. Gilbourne, N.L.D. Chatzisarantis and A.C. Sparkes. 'Research methods in sport and exercise psychology: Quantitative and qualitative issues'. Journal of Sports Sciences 19 (2001): 777-809.

55 Bloor, M., J. Frankland, M. Thomas and K. Robson. Focus Groups in Social Research. London: Sage, 2001.

56 Janesick, V.J. 'The dance of qualitative research. Design, metaphor, methodolatry and meaning'. In Handbook of Qualitative Research, ed. N.K. Denzin and Y.S. Lincoln, 209-219. London: Sage. 1994

57 Dale, G.A. 'Existential phenomenology: Emphasizing the experience of the athlete in sports psychology research'. The Sports Psychologist 10 (1996): 307-321.

58 Tierney, G.W. 'Get real: representing reality'. International Journal of Qualitative Studies in Education 15 (2002): 385-398.

59 Gilbourne, D. and D. Richardson. 'A practitioner-focused approach to the provision of psychological support in soccer: Adopting action research themes and processes'. Journal of Sports Sciences 23, no 6 (2005): 651-658. 
60 Butcher, Z., S. Fairclough, G. Stratton and D. Richardson. 'The Effect of Feedback and Information on Children's Pedometer Step Counts at School'. Pediatric Exercise and Science 19 (2007): 29-38.

61 Van Sluijs, E.M.F., A.M. McMinn and S.J. Griffin. 'Effectiveness of interventions to promote physical activity in children and adolescents: systematic review of controlled trials'. British Medical Journal 355, no 703 (2007).

62 Dwyer, J.J., K.R. Allison, E.R. Goldenberg, A.J. Fein, K.K. Yoshida and M.A. Boutilier. 'Adolescent girls' perceived barriers to participation in physical activity'. Adolescence 41 (2006) 75-89.

63 Salmela, J.H. 'Learning from the development of expert coaches'. Coaching and Sport Science Journal 2, no 2 (1995): 3-13.

64 Borrie, A. and Z. Knowles. 'Coaching science and soccer'. In Science and Soccer Second Edition, ed. T. Reilly and A.M. Williams, 187-197. London: Routledge. 2003

65 Smoll, F.L. and R.E. Smith. 'Educating youth sport coaches: an applied sport psychology perspective'. In Applied Sports Psychology: Personal Growth to Peak Performance, ed. J.M. Williams, 36-50. Mountain View: Mayfield Publishing. 1993

66 Spencer, A.F. 'A case-study exemplary American College Physical Educator-tennis coach'. International Journal of Sport Pedagogy 3 (2001): 127.

67 Cote, J., J.H. Salmela, P. Trudel, A. Baria and S.J. Russell. 'The coaching model: a grounded assessment of gymnastics coaches' knowledge'. Journal of Sport and Exercise Psychology 17 (1995): 1-17.

68 Potrac, P., R. Jones and K. Armour. "It's All About Getting Respect': The Coaching behaviours of an Expert English Soccer Coach'. Sport, Education and Society 7, no 2 (2002): 183-202. 
69 Zeichner, K. and J.Gore. 'Teacher socialization'. In Handbook of research on teacher education, ed. W.R. Houston, 329-348. New York: Macmillan. 1990

70 Kuzmic, J. 'A beginning teacher's search for meaning: Teacher socialization, organizational literacy, and empowerment'. Teacher and Teacher Education 10, no 1 (1994): 15-27.

71 Knowles, Z.., D. Gilbourne, A. Borrie and A. Nevill. 'Developing the Reflective Sports Coach: a study exploring the processes of reflective practice within higher education coaching programmes'. Reflective Practice 2, no 2 (2001): 185-207.

72 Lyle, J. 'Coaches' decision making'. In The Coaching Process: principles and practice for sport, ed. N. Cross and J. Lyle, 210-232. Oxford: Butterworth Heinemann. 1999 